\title{
Characterisation of the high-protein-induced effects on tissue protein synthesis rates and accretion in rats
}

\author{
L. Chevalier, C. Bos, D. Azzout-Marniche, A. Payet, D. Tomé and C. Gaudichon \\ UMR914 INRA-AgroParisTech Physiologie de la Nutrition et du Comportement Alimentaire, Paris, France
}

It has previously been demonstrated in rats that a very-high-protein low-carbohydrate diet is associated with a strong inhibition of hepatic protein synthesis rates, particularly in the fed state, while no change is observed in skeletal muscle (N Chotechuang, L Chevalier, D Azzout-Marniche, C Luengo, D Tomé, C Gaudichon and C Bos, unpublished results). The objectives of the present work were: (1) to identify the respective roles of elevated protein intake and the confounding influence of macronutrient exchanges on the metabolic response, particularly through the modulation of insulin secretion by carbohydrate (CHO) intake; (2) to test whether a moderately-highprotein diet produces the same effects as a very-high-protein diet in relation to hepatic protein synthesis.

Male Wistar rats ( $n$ 96) were adapted to eight isoenergetic diets with normal, intermediate or high protein (total milk protein) levels (\% energy; 14 (NP), 33 (IP) or 50 (HP) respectively) and different combinations of fat and CHO contents. After a 2-week adaptation period rats (twelve per group) were killed in the fasted or fed state after injection of a flooding dose of $\left[{ }^{13} \mathrm{C}\right]$ valine to measure tissue protein fractional synthesis rates (FSR). Tissue protein content was measured by elemental analysis coupled with isotope-ratio (IR) MS. $\left[{ }^{13} \mathrm{C}\right]$ valine enrichment of tissue protein and free amino acids were determined by GC-combustion-IRMS and GC-MS respectively.

Increasing the dietary protein level was associated with a significant rise in uraemia $(P<0.05)$ and the hepatic protein pool $(P<0.05)$ and a significant decrease in both hepatic FSR $(P<0.0001)$ and the absolute synthesis rate of protein $(P<0.005)$. All these changes were independent of the CHO:fat of the diets. Skeletal muscle FSR remained insensitive to all the macronutrient exchanges. Dietary fat and $\mathrm{CHO}$ only influenced the protein content of the kidneys and skeletal muscle and liver mass, which were positively correlated with both protein intake and CHO:fat intake. Dietary protein affected hepatic FSR in a dose-dependent manner; mean FSR (\%/d) of rats receiving NP, IP or HP levels reached 110, 92 and 82 respectively.

The present study confirms the previous results (N Chotechuang, L Chevalier, D Azzout-Marniche, C Luengo, D Tomé, C Gaudichon and $\mathrm{C}$ Bos, unpublished results) and provides new insights by showing that increasing protein intake modulates hepatic protein metabolism independently of the parallel changes in $\mathrm{CHO}$ and associated changes in insulin levels. Moreover, it shows that the intensity of the response is proportional to the increase in dietary protein. By contrast, muscle protein synthesis rates remain insensitive to any dietary manipulation in this model of sedentary rats.

Study supported by Arilait Recherches. 